\title{
Clients' Satisfaction with Services for Prevention of Mother-to-Child Transmission of HIV in Public Health Facilities in Diredawa City, Eastern Ethiopia
}

This article was published in the following Dove Press journal: HIVIAIDS - Research and Palliative Care

\author{
Kinfe Abayneh' \\ Bizatu Mengistie ${ }^{2}$ \\ Lemessa Oljira ${(\mathbb{D})^{3}}^{3}$ \\ Getahun Tiruye ${ }^{4}$ \\ 'Department of Management and Health \\ Policy, Sofi Health Center, Harar, \\ Ethiopia; ${ }^{2}$ Department of Environmental \\ Health, College of Health and Medical \\ Sciences, Haramaya University, Harar, \\ Ethiopia; ${ }^{3}$ School of Public Health, \\ College of Health and Medical Sciences, \\ Haramaya University, Harar, Ethiopia; \\ ${ }^{4}$ Department of Midwifery, College of \\ Health and Medical Sciences, Haramaya \\ University, Harar, Ethiopia
}

Background: Ethiopia has a very high burden of HIV infection among children, contracted from their mothers, and nearly two-thirds of pregnant women do not receive prevention of mother-to-child transmission (PMTCT) services. Ensuring clients' satisfaction with PMTCT services is one of the bases to scale up service utilization and mitigate MTCT of HIV. However, in Ethiopia, particularly in the study area, evidence related to clients' satisfaction with PMTCT services is scanty.

Methods: A facility-based cross-sectional study was conducted among women attending antenatal care in Diredawa city. Systematic random sampling was used to select 517 study participants. Interviewer-administered structured and pretested questionnaires were used to collect data. Statistical significance was regarded as $P \leq 0.05$ with a $95 \%$ CI.

Results: Client satisfaction with PMTCT services was 82.2\% (95\% CI 66.4\%-94.3). Receiving the service from a hospital (AOR 2.34; 95\% CI 1.5, 3.98), no formal education (AOR 2.53, 95\% CI 1.52-4.2), primary education (AOR $2.1795 \%$ CI 1.17-4.04), receiving pre- and post-HIV test counseling from the same provider (AOR 4.93, 95\% CI 2.98-7.17), gestational age above first trimester (AOR 1.74, 95\% CI 1.12-2.71), and waiting time $\leq 15$ minutes (AOR 2.31, 95\% CI 1.28-4.16) were positively associated with client satisfaction with PMTCT services.

Conclusion: Client satisfaction with PMTCT services is relatively high. Receiving the service from a hospital, no formal education or only primary education, gestational age above first trimester, getting pre- and post-HIV test counseling from the same provider, and waiting time $\leq 15$ minutes to receive services were factors associated with client satisfaction. A greater number of skilled PMTCT-service providers would improve service quality and hasten its delivery. Furthermore, providing mentoring and supportive supervision of health centers with PMTCT programs and keeping the same provider in posttest counseling is also mandatory.

Keywords: ANC, HIV, counselors

\section{Background}

Mother-to-child transmission (MTCT) of HIV can occur during pregnancy, labor, childbirth, and breastfeeding. ${ }^{1,2}$ Globally, approximately 38 million people are currently living with HIV, and tens of millions of people have died due to AIDS-related causes since the beginning of the epidemic. ${ }^{3}$ Although there have been significant declines in new infections since the mid-1990s, there were still about 1.7 million new infections in $2019 .{ }^{4}$

HIV remains a leading cause of death globally among women of reproductive

Correspondence: Getahun Tiruye Email gtiruye@gmail.com

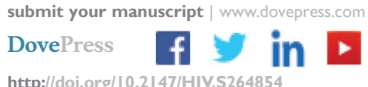

http://doi.org/| 0.21 477/HIV.S264854
HIVIAIDS - Research and Palliative Care 2020:12 6II-620

6 I I

(c) (i) () 2020 Abayneh et al. This work is published and licensed by Dove Medical Press Limited. The full terms of this license are available at https://www.dovepress.com/terms. (c) ${ }_{\mathrm{BY}}$ NC php and incorporate the Creative Commons Attribution - Non Commercial (unported, v3.0) License (http://creativecommons.org/licenses/by-nc/3.0/). By accessing the work you hereby accept the Terms. Non-commercial uses of the work are permitted without any further permission from Dove Medical Press Limited, provided the work is properly attributed. For permission for commercial use of this work, please see paragraphs 4.2 and 5 of our Terms (https://www.dovepress.com/terms.php). 
treatment scaling up, ${ }^{5}$ and AIDS-related death had been reduced to 690,000 in 2019 , a $37 \%$ decrease from 1.1 million in $2010 .^{5,6}$ About $80 \%$ of pregnant women living with HIV were receiving antiretroviral treatment in the year 2017. This can be considered a significant improvement compared to 2010 , when only $51 \%$ had access to the treatment. $^{7}$ Despite this significant progress, 740,000 women of reproductive age became HIV-positive. Nearly three-quarters of these women live in 23 countries. The vast majority are in sub-Saharan Africa and are classified as high priority for the prevention of MTCT (PMTCT), as reported by the Joint United Nations Programme on HIV/ AIDS. ${ }^{7,8}$

Pregnant women and children aged $<15$ years in subSaharan Africa account for around two-thirds of the world's HIV infections, and this in turn has serious complications for children born to positive women. ${ }^{9}$ In this regard, in 2019 it was estimated that around 150,000 children were newly infected with $\mathrm{HIV}^{10}$ of which $>90 \%$ of them were infected through MTCT. ${ }^{11,12}$ In the absence of treatment, about half these infected children will die before their second birthday. ${ }^{11}$ Although there is progress in increasing availability of free antenatal care (ANC) and PMTCT programs in sub-Saharan Africa, the rate of MTCT of HIV is still $15 \%-40 \% .^{13}$

Ethiopia is one of the east African countries to have been highly affected by HIV. ${ }^{14,15}$ As a 2016 report indicates, around 20,000 people have died due to the virus. ${ }^{14,16}$ Similarly, Ethiopia is also among the ten countries in the world with the highest number of children infected by MTCT, ${ }^{17}$ and the rate of MTCT of HIV, including breastfeeding, is about $15.9 \% .{ }^{16}$ Accordingly, in 2007 Ethiopia started universal screening of pregnant women for HIV, and in a majority of cases HIV testing during pregnancy is provided as part of ANC. ${ }^{2}$ However, progress is not satisfactory: only two-thirds of pregnant women had an ANC visit, ${ }^{18}$ below the WHO goal for HIV screening $(80 \%) .{ }^{11}$ Though universal screening was adopted, the 2012-2013 report showed that even among mothers who had attended ANC, more than a third had not been tested for HIV, ${ }^{19}$ thus representing a significant missed opportunity for provision of PMTCT services. ${ }^{19,20}$

The Federal Ministry of Health also recognized and accepted the vision of an HIV-free generation endorsed by UNAIDS to reduce HIV MTCT to $<2 \%$ by $2020 .^{2,21}$ To achieve this goal, HIV screening during pregnancy should be raised to $>95 \%$. $^{22}$ Thus, ensuring client satisfaction while delivering PMTCT services has significant benefit in optimizing uptake, adherence, and retention throughout care for better outcomes. ${ }^{23,24}$ Strengthening the linkage of PMTCT services within maternal, newborn, child health, sexual and reproductive health, and family-planning services in health facilities is one of the strategies for addressing PMTCT targets. ${ }^{25}$ Client satisfaction with PMTCT services is an indicator of quality of service and is one of the measures of desired outcomes in health care, ${ }^{25,26}$ as it influences service utilization. ${ }^{27}$ Despite assessing and addressing client satisfaction being of paramount importance in scaling up PMTCT-service utilization, there is scant proof concerning magnitude and factors associated with client satisfaction with PMTCT services, particularly in Diredawa city, eastern Ethiopia.

\section{Methods}

\section{Study Area, Period, and Design}

This study was conducted in Diredawa city, eastern Ethiopia, which is located $515 \mathrm{~km}$ from the capital city Addis Ababa. The population of the city is estimated to be 388,279 . Of this population, 194,770 (50.1\%) are male and 193,509 (49.8\%) are female. ${ }^{28}$ This facility-based cross-sectional study was conducted from January to February 2018.

\section{Study Participants}

All women attending ANC in public health facilities of Diredawa city were the source population. Women who visited the selected health facilities for ANC services were included as the study population.

\section{Sample Size and Sampling Technique}

A single population-proportion formula was used to determine sample size: assumption of a 95\% significance level, 4\% margin of error, $71.2 \%$ client satisfaction with PMTCT services in public health facilities, ${ }^{26}$ and a $5 \%$ non-response rate. The final sample size was determined to be 517. There are ten public health facilities in Diredawa city, and of these, five public health facilities were selected by lottery. Proportional allocation was used to select the sample from ANC units of selected health facilities. Finally, systematic random sampling was applied to recruit study participants. The study purposively selected and observed 15 clients-provider counseling sessions in both pretest and posttest HIV/AIDScounseling services. 


\section{Data Collection}

We used a standardized questionnaire adapted from a UNAIDS best-practice tool that focuses on HIV/AIDS-counseling services to measure client satisfaction. ${ }^{26,29}$ Structured questionnaires containing sociodemographic and obstetric characteristics of respondents, comfort with counselors' approaches, privacy during counseling, topics of discussion during HIV counseling, and understandability of messages during ANC was used to measure a more nuanced understanding of client satisfaction. ${ }^{23,26,30-32}$ Furthermore, serviceprovision processes were also observed for 15 client-counseling sessions using a checklist. ${ }^{23,25,26,33}$ Interviewer-administered questionnaires were prepared first in English and then translated into Amharic and Afan Oromo as per the mother tongue of the participants and translated back into English for consistency by language experts. Pretesting was done on 5\% of the total sampled population at Hiwot Fana Specialized University Hospital, then corrections and modification of the tool were carried out accordingly.

\section{Data Collectors}

Five diploma midwives and two supervisors not working in the selected health facilities were involved as data collectors. Exit interviews of clients were done by trained data collectors. The investigators and supervisors closely followed the data-collection process throughout the data-collection period. Each day, data collected were checked for completeness and corrective measures taken accordingly.

\section{Operational Definitions PMTCT Services}

These comprised a package of services that included primary prevention of HIV in women, prevention of unintended pregnancy among HIV-infected women, interventions to reduce transmission from $\mathrm{HIV}$-infected pregnant and lactating women to their children, and care and support of women, children, and families infected and affected by HIV. ${ }^{11}$

\section{Client Satisfaction}

This was defined as client perception of the service or product in terms of meeting or even exceeding their expectations. $^{23}$ Client satisfaction was measured using the questionnaire with a 14-item scale. We used a fivepoint Likert-scale instrument, in which 5 denoted very satisfied and 1 very dissatisfied. ${ }^{26}$ Satisfaction level was assessed using a five-pont Likert scale (1 very dissatisfied, 2 dissatisfied, 3 neutral, 4 satisfied, and 5 very satisfied).

\section{Waiting Time}

This refers to the period for which clients were expected to wait before receiving services.

\section{Data Processing and Analysis}

Data were first coded, then double-entered on EpiData version 3.1 and exported into SPSS version 21 for analysis. For the purpose of analysis, the five-item Likert scale was changed to a binary outcome variable (satisfied and dissatisfied). Accordingly, those who responded "very satisfied" and "satisfied" were categorized as satisfied clients and those who responded "neutral", "dissatisfied", and "very dissatisfied" were categorized as unsatisfied. ${ }^{26}$

Descriptive statistics were used to analyze each variable, and results are summarized in the tables. HosmerLemeshow and omnibus goodness-of-fit tests were used to assess whether necessary assumptions for the application of logistic regression met. Variables with $P$-value $\leq 0.25$ on bivariate logistic regression were considered in the multivariable model. Crude odds ratios (CORs) and adjusted odds ratios (AORs) with 95\% CI were calculated, and variables with $P$-value $\leq 0.05$ on multivariable analysis were deemed statistically significant.

\section{Ethical Considerations}

Ethical clearance was obtained from the Institute of Health Research Ethical Review Committee of Haramaya University College of Health and Medical Sciences. Permission letters were obtained from Diredawa Health Bureau and each of public health facilities prior to the study. Voluntary written and signed consent was obtained from each study participant after informing them of the objectives of the study, confidentiality, right to withdrawal, benefits, and risks. This study was conducted in accordance with the Declaration of Helsinki.

\section{Results}

\section{Sociodemographic Characteristics of Study Participants}

A total of 516 pregnant women were involved in the study, making a response rate of $99.8 \%$. More than half $(52.9 \%)$ of the participants were hospital attendants and their mean age was $24.74 \pm 4.3$ years. A majority $(94.6 \%)$ were married, and $83.5 \%$ were urban residents. Two-thirds $(65.5 \%)$ of the study participants were housewives (Table 1). 
Table I Sociodemographic Characteristics of Participants $(n=5 \mid 6)$

\begin{tabular}{|c|c|c|c|}
\hline Variable & Category & Frequency & Percentage \\
\hline \multirow[t]{2}{*}{ Age, years } & $18-24$ & 287 & 55.6 \\
\hline & $\geq 25$ & 229 & 44.4 \\
\hline \multirow[t]{2}{*}{ Residence } & Urban & 431 & 83.5 \\
\hline & Rural & 85 & 17.5 \\
\hline \multirow[t]{4}{*}{ Religion } & Muslim & 294 & 56.9 \\
\hline & Orthodox & 181 & 35.0 \\
\hline & Protestant & 35 & 6.9 \\
\hline & Other & 6 & 1.2 \\
\hline \multirow[t]{4}{*}{ Ethnicity } & Oromo & 189 & 36.6 \\
\hline & Somali & 175 & 33.9 \\
\hline & Amhara & 127 & 24.6 \\
\hline & Other $^{\mathrm{a}}$ & 25 & 4.8 \\
\hline \multirow[t]{4}{*}{ Marital status } & Married & 488 & 94.6 \\
\hline & Single & 13 & 2.5 \\
\hline & Divorced & 9 & 1.7 \\
\hline & Other $^{\mathrm{b}}$ & 6 & 1.2 \\
\hline \multirow[t]{4}{*}{ Education } & Unable to read and write & 148 & 28.7 \\
\hline & Read and write only & 80 & 15.5 \\
\hline & Primary & 160 & 31.0 \\
\hline & Secondary and above & 128 & 24.8 \\
\hline \multirow[t]{5}{*}{ Occupation } & Housewife & 338 & 65.5 \\
\hline & Government employee & 88 & 17.1 \\
\hline & Merchant & 71 & 13.8 \\
\hline & Daily laborer & 8 & 1.5 \\
\hline & Other ${ }^{c}$ & 11 & 2.1 \\
\hline
\end{tabular}

Notes: ${ }^{a}$ Tigray, Gurage, and Wolayita; 'bidowed and separated; ${ }^{\text {c }}$ armer and student.

\section{Obstetric and PMTCT-Related Factors}

The average gestational age of current pregnancy was 25.7 weeks. More than half $(54.5 \%)$ of the study participants were multigravida, and a majority (88.3\%) had come primarily for ANC follow-up. Almost all (98\%) had heard about the presence of PMTCT services before they came to the health facility for ANC, and their main source of information for PMTCT services was health-care providers (72\%). The duration of the counseling sessions was 5-60 minutes, with an average of 20 minutes. Regarding counseling services, more than half $(56.2 \%)$ of the participants received both pretest and posttest HIV counseling from the same counselor. During the counseling sessions, a majority $(87 \%)$ did not face a language barrier (Table 2).

\section{Client Responses Regarding PMTCT- Related Issues}

Concerning client responses on the benefit of PMTCT services, almost all (99\%) participants found that PMTCT- service counseling was beneficial and $86.1 \%$ liked the discussion on HIV/AIDS. Most (97.1\%) were happy with the opening hours of the health facilities. Similarly, most (96\%) were happy with the sessions and recommended the importance of the services to others. Over half (59.4\%) of the participants had come to the health facilities on others' recommendations, and only $3.9 \%$ of the participants preferred it that HIV/AIDS would not be discussed during their antenatal visit.

\section{Observation of Pre- and Posttest Counseling Sessions}

Fifteen counseling sessions were observed during pre- and posttesting. In all of the 15 observations that were made, the counselor had received the women in a welcoming manner and created a trusting or supportive rapport. It was observed that the counselor listened to women's ideas and concerns in 12 of the 15 sessions and invited to ask questions in six. The 
Table 2 Obstetric and PMTCT Variables $(n=516)$

\begin{tabular}{|c|c|c|c|}
\hline Variable & Category & Frequency & Percentage (\%) \\
\hline \multirow[t]{2}{*}{ Type of institution at which they received PMTCT services } & Health center & 272 & $52.9 \%$ \\
\hline & Hospital & 244 & $47.1 \%$ \\
\hline \multirow[t]{2}{*}{ Trimester of current pregnancy } & $\leq$ First & 80 & 15.5 \\
\hline & $>$ First & 436 & 83.5 \\
\hline \multirow[t]{4}{*}{ Number of ANC visits } & times & 169 & 32.9 \\
\hline & Two & 165 & 32.8 \\
\hline & Three & 121 & 23.4 \\
\hline & Four & 61 & 11.8 \\
\hline \multirow[t]{2}{*}{ Gravidity } & Primigravida & 282 & 54.5 \\
\hline & Multigravida & 234 & 45.5 \\
\hline \multirow[t]{3}{*}{ Parity } & Nullipara & 290 & 56.2 \\
\hline & Multipara & 202 & 39.1 \\
\hline & Grand multipara & 24 & 4.7 \\
\hline \multirow[t]{3}{*}{ Reason for visiting ANC clinic } & ANC & 456 & 88.3 \\
\hline & HIV test & 40 & 7.7 \\
\hline & Both ANC and HIV test & 20 & 3.9 \\
\hline \multirow[t]{2}{*}{ Have you received information about the PMTCT service before? } & Yes & 506 & 98.0 \\
\hline & No & 10 & 2.0 \\
\hline \multirow[t]{4}{*}{ Common sources of information about PMTCT service } & Health workers & 371 & 72.0 \\
\hline & Mass media & 87 & 17.0 \\
\hline & Friends & 34 & 6.5 \\
\hline & Health-extension workers & 24 & 4.5 \\
\hline \multirow[t]{2}{*}{ Waiting time to see service provider } & $\leq 15$ minutes & 282 & 54.7 \\
\hline & $>15$ minutes & 234 & 45.3 \\
\hline \multirow[t]{2}{*}{ Duration of counseling session } & $\leq 20$ minutes & 362 & 70.2 \\
\hline & $>20$ minutes & 154 & 29.8 \\
\hline \multirow[t]{2}{*}{ Time taken to reach health facility } & $\leq 30$ minutes & 368 & 71.4 \\
\hline & $>30$ minutes & 148 & 28.6 \\
\hline \multirow[t]{2}{*}{ Pre- and posttest counseling given by same counselor } & Yes & 290 & 56.2 \\
\hline & No & 226 & 38.8 \\
\hline \multirow[t]{2}{*}{ Sex of counselor } & Female & 296 & 57.4 \\
\hline & Male & 220 & 42.6 \\
\hline \multirow[t]{2}{*}{ Did you face a language barrier? } & Yes & 449 & 87.0 \\
\hline & No & 67 & 13.0 \\
\hline
\end{tabular}

counselors also attempted to respond to each of the questions raised. In all observed sessions, such counselor qualities as avoiding judgment or disapproval, treating the women with empathy, dignity, and respect, using language that could be easily understood by the women, and maintaining privacy were seen. Counselors checked to be sure that the women understood the information provided for all 15 observed sessions.
In all pretest counseling sessions, it was observed that counselors introduced and oriented the session for the women, prepared them well for the HIV test, explored options for reducing risk, and assessed them for possible risks. Posttest counseling for negative results was performed similarly in all the observed sessions. Negative HIV-test results were provided, riskreduction plans negotiated, support for risk-reduction 
plans identified, and disclosure and partner referral negotiated. Finally, the importance of retesting following a window period was discussed in all counseling sessions.

\section{Participants' Satisfaction with PMTCT- Service Components}

Most (96.6) of the participants were satisfied or very satisfied with the provider's greeting. The same proportion were satisfied or very satisfied with the adequacy of time for counseling and counselors' respect. However, more than half $(55.0 \%)$ were dissatisfied with the availability of laboratory services when needed (Table 3 ).

\section{Participants' Overall Satisfaction with PMTCT Services}

Of the 516 study participants, 424 (82.2\%, 95\% CI $66.4 \%-94.3 \%$ ) clients were satisfied with the PMTCT component of HIV services.

\section{Factors Affecting Client Satisfaction with PMTCT Services}

The final multivariable logistic regression analysis showed that receiving counseling services from a hospital increased the odds of client satisfaction compared to those who received these from a health center (AOR 2.34, 95\% CI 1.5-3.8). Similarly, receiving both pre- and posttest counseling from the same provider (AOR 3.62, $95 \%$ CI 2.98-7.17) increases the odds of client satisfaction compared to their counterparts. Client satisfaction increased for those who had no formal education (AOR $2.53,95 \%$ CI $1.52-4.20)$ and those with primary education (AOR 2.17, 95\% CI 1.17-4.04) and these were found to have a statistically significant association with PMTCTservice satisfaction. Furthermore, gestational age above first trimester (AOR 1.74, 95\% CI 1.12-2.71) and waiting time $\leq 15$ minutes (AOR 2.31, 95\% CI 1.28,4.16) were significantly associated with client satisfaction with PMTCT services compared to their counterparts (Table 4).

\section{Discussion}

In this study, $82.2 \%$ of clients were satisfied with PMTCT services, in line with a finding reported from Sebeta, Ethiopia $(80.7 \%),{ }^{34}$ but lower than findings reported in Tanzania $(92 \%)^{33}$ and Hadiya, Ethiopia (90\%). ${ }^{35}$ This discrepancy might be due to differences in study settings. This study was conducted with urban clients, who are more aware of the option of treatment available, as they are frontline for information about PMTCT-related issues. As such, this could make them less likely to be involved in counseling sessions. On the other hand, clients living in rural settings might not have adequate knowledge on what is expected from counselors during sessions or might not be aware of the unavailability of laboratory services, making them easily satisfied. ${ }^{23,35}$ In contrast, higher prevalence of client satisfaction was identified in this study than studies in Adama $(74.7 \%)^{26}$ and Dodoma, Tanzania $(75.2 \%) .^{23}$ This high proportion might be due to differences in study period or geographical variation.

Table 3 Client Satisfaction with Different Aspects of PMTCT Services $(n=5 \mid 6)$

\begin{tabular}{|l|l|l|l|l|l|}
\hline \multirow{2}{*}{ Item } & Very Dissatisfied & Dissatisfied & Neutral & Satisfied & Very Satisfied \\
\cline { 2 - 5 } & $\mathbf{n}(\%)$ & $\mathbf{n}(\%)$ & $\mathbf{n}(\%)$ & $\mathbf{n}(\%)$ & $\mathbf{n}(\%)$ \\
\hline Provider's greeting polite and friendly & $\mathrm{I}(0.2)$ & $\mathrm{II}(2.1)$ & $5(1.0)$ & $324(62.8)$ & $175(33.9)$ \\
Satisfaction with waiting-room comfort? & $4(0.8)$ & $52(9.3)$ & $26((5.0)$ & $336(65.1)$ & $98(19.0)$ \\
Waiting time & $7(1.4)$ & $4 I(8.3)$ & $16(3.1)$ & $364(70.5)$ & $88(17.1)$ \\
Counseling-room comfort & $6(1.2)$ & $52(10.1)$ & $21(4.1)$ & $314(60.9)$ & $123(23.8)$ \\
Privacy of counseling room & $4(0.8)$ & $43(7.8)$ & $35(6.7)$ & $285(52.2)$ & $149(28.7)$ \\
Adequacy of time for counseling & $3(0.6)$ & $15(2.9)$ & $11(2.1)$ & $332(64.4)$ & $155(30.0)$ \\
Counselor's respect & $2(0.4)$ & $19((3.7)$ & $9((1.7)$ & $345(66.7)$ & $141((27.3)$ \\
Provider confidentiality & $7(1.4)$ & $20(3.9)$ & $14(2.7)$ & $367(71.1)$ & $108(20.9)$ \\
Counselor's explanation of test(s) & $3(0.6)$ & $74(14.3)$ & $47(9.1)$ & $281(54.5)$ & $111(21.5)$ \\
Counselors' competence & $2(0.4)$ & $76(14.7)$ & $46(8.9)$ & $313(60.7)$ & $79(15.3)$ \\
Cleanliness and sanitation of procedure & $5(0.9)$ & $49(9.4)$ & $30(5.9)$ & $363(70.3)$ & $69(13.4)$ \\
Laboratory service always available when needed & $6(1.2)$ & $158(33.1)$ & $120(20.7)$ & $180(34.9)$ & $52(10.1)$ \\
Clear explanation of appointment date & $3(0.6)$ & $51(9.9)$ & $29(5.7)$ & $299(57.9)$ & $134(26.0)$ \\
Availability of PMCT information & $1(0.2)$ & $68(13.2)$ & $35(6.8)$ & $289(56.0)$ & $123(23.8)$ \\
\hline
\end{tabular}


Table 4 Bivariate and Multivariable Analyses of Factors Associated with Client Satisfaction with PMTCT Services ( $n=5$ I6)

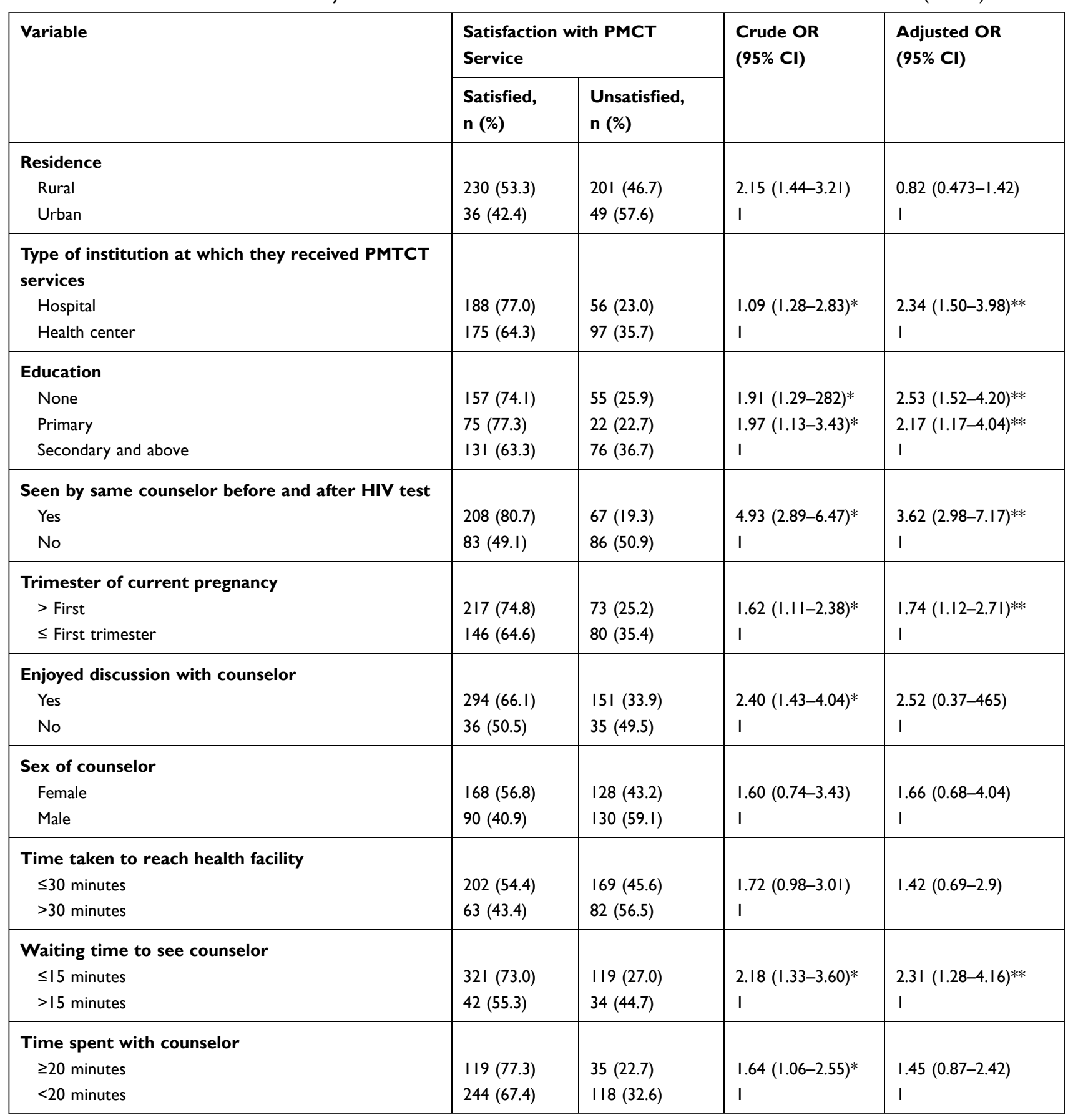

Notes: *Statistically significant on bivariate analysis only; **statistically significant on both bivariate and multivariate analyses.

Ethiopia has taken many steps to resolve some of the barriers facing women when seeking maternity services. From these measures, the inclusion of prenatal, delivery, and postnatal care were listed as services free of charge. ${ }^{36}$ However, there are serious constraints on the continuous supply of equipment or precursors for laboratory investigation, which causes clients not to get the necessary services or exposes them to charges for these services. As such, unavailability of laboratory services will profoundly lower clients' perceived quality of care or satisfaction. ${ }^{37}$ Similarly, this study revealed that more than half $(55.0 \%)$ of the participants were not satisfied with the availability of certain laboratory services.

The present study found that client satisfaction with PMTCT services was nearly twice as times common among respondents with no formal and primary education 
than those with secondary education and above. Likewise, a similar finding was found in Dodoma, Tanzania. ${ }^{23}$ This might be due to educated clients being more aware of PMTCT-related information or educated groups being less satisfied than less educated groups, because of higher-quality service expectations. Moreover, participants with higher education may inappropriately consider themselves as more knowledgeable and at lower risk of infection and thus fail to participate actively in counseling sessions. ${ }^{38}$ The finding of this study revealed that the odds of client satisfaction with PMTCT services were 2.34 times higher among participants who accessed the services from a hospital than their counterparts. This may be the impact of unavailability of necessary laboratory services at health centers. Similarly, participants in this study were not satisfied with laboratory services. This is due to lack of adequate supplies and skilled personnel to provide appropriate services in health centers compared to hospitals. $^{35}$

Gestational age was significantly associated with client satisfaction with PMTCT services. The odds of being satisfied with PMTCT services were 1.74 times higher among participants with gestational age above first trimester than their counterparts. This was in agreement with a study conducted in Addis Ababa, Ethiopia. ${ }^{39}$ A possible explanation might be that clients in their first trimester usually have yet to be exposed to PMTCT services. Therefore, this unfamiliarity with the services might limit their interaction with providers and hence, hinder their full participation in the services. Client satisfaction with PMTCT services was 1.45 times more common among participants who waited for $\leq 15$ minutes than their counterparts. This result was congruent with studies carried out in Nigeria ${ }^{31}$ and Tanzania. ${ }^{23}$ This might be due to the fact that clients usually relate waiting time to the kind of service they are going to receive or clients liking to receive a service with minimal waiting time, making them satisfied without considering the quality of services.

HIV-testing and -counseling guidelines for PMTCT recommend that both pretest and posttest counseling be offered by the same counselor. Keeping the same provider in pre- and post-HIV-test counseling helps to secure client confidentiality and privacy and ensure client satisfaction.${ }^{40,41}$ Receiving pre- and post-HIV test counseling from the same provider is positively associated with client satisfaction with PMTCT services. ${ }^{23,26,31,39}$ This study used a validated and standardized questionnaire that had been tested and revised to assess client satisfaction with PMTCT services, and we also observed specific client-provider interaction while delivering services. However, the scope is limited in addressing all factors that can probably affect client satisfaction with PMTCT services.

\section{Conclusion}

Client satisfaction with PMTCT services was relatively high. However, more than half of the participants were not satisfied with availability of laboratory services. No formal education, primary education, receiving services from a hospital, with the same counselor in pretest and posttest HIV counseling, and gestational age above first trimester were positively associated with client satisfaction with PMTCT services. Furthermore, waiting time $\leq 15$ minutes was positively associated with PMTCT-service satisfaction. Therefore, mentoring and supportive supervision of health centers with PMTCT programs, ensuring availability of supplies and equipments for necessary laboratory investigations, and providing pre- and posttest HIV counseling by the same provider would improve clients' PMTCT satisfaction. Moreover, there should be an increase in the number of skilled PMTCT-service providers to further optimize quality in general and speed up service delivery in particular.

\section{Data-Sharing Statement}

All related data have been presented within the manuscript. The data set supporting the conclusions of this article is available from the authors upon reasonable request.

\section{Acknowledgments}

We would like to acknowledge Haramaya University for their technical and financial support of this study. Next, our gratitude goes to all data collectors and supervisors. Last but not least, thanks to all ANC attendees who participated in the study. Without them, this research would not have been realized.

\section{Author Contributions}

$\mathrm{KA}, \mathrm{BM}, \mathrm{LO}$, and GT conceived and designed the study, KA, $\mathrm{BM}$, and GT used the data-collection instrument to collect data, KA, BM, LO, and GT cleaned and analyzed the data and interpreted findings, KA and GT drafted the manuscript, and KA, BM, LO, and GT provided critical revision and approval of the final manuscript. All authors contributed to data analysis, drafting or revising the article, have agreed on the journal to which the article will be submitted, gave final 
approval to the version to be published, and agree to be accountable for all aspects of the work.

\section{Disclosure}

The authors declare no conflicts of interest in this work.

\section{References}

1. Federal Democratic Republic of Ethiopia. Country progress report on the HIV Response, 2014. Addis Ababa, Ethiopia; 2014:1-50.

2. Federal HIV/AIDS Prevention and Control Office Federal Ministry of Health. Guidelines for prevention of mother to child transmission of HIV in Ethiopia. Addis Ababa, Ethiopia; 2007:1-42.

3. Global AIDS Update. Seizing the moment, tackling entrenched inequalities to end epidemics. Available from: http://aidsinfo.unaids. org/. Accessed September 10, 2020.

4. Press release. UNAIDS report on the global AIDS epidemic shows that 2020 targets will not be met because of deeply unequal success; COVID-19 risks blowing HIV progress way off course. Available from: https://www.unaids.org/en/resources/presscentre/pressrelea seandstatementarchive/2020/july/20200706_global-aids-report. Accessed September 10, 2020.

5. Women and HIV. A spotlight on adolescent girls and young women. Available from: https://www.unaids.org/en/resources/documents/ 2019/women-and-hiv. Accessed September 10, 2020.

6. UNAIDS. Fact sheet on global HIV statistics. 2016:1-6.

7. UNAIDS. (AIDS info), miles to go: global AIDS update. 2018.

8. Joint United Nations Programme on HIV/AIDS. Start free stay free AIDS free 2017 progress report. 2017:1-78.

9. Kharsany AB, Karim QA. HIV infection and AIDS in Sub-Saharan Africa: current status, challenges and opportunities. Open AIDS $J$ 2016;10:34.

10. UNICEF. Global and regional trends: while there has been promising progress in the HIV response, children continue to be affected by the epidemic. 2019.

11. WHO. PMTCT strategic vision 2010-2015: preventing mother-tochild transmission of HIV to reach the UNGASS and Millennium Development Goals. Geneva, Swizerland; 2010:1-34.

12. WHO. WHO recommendations on the diagnosis of HIV infection in infants and children. Geneva, Swizwrland; 2010.

13. Yah CS, Tambo E. Why is mother to child transmission (MTCT) of HIV a continual threat to new-borns in sub-Saharan Africa (SSA). $J$ Infect Public Health. 2019;12(2):213-223. doi:10.1016/j.jiph.2018.10.008

14. Rajasingham R, Smith RM, Park BJ, et al. Global burden of disease of HIV-associated cryptococcal meningitis: an updated analysis. Lancet Infect Dis. 2017;17(8):873-881. doi:10.1016/S1473-3099 (17)30243-8

15. HIV and AIDS in East and southern africa regional overview. Available from: https://www.avert.org/professionals/hiv-aroundworld/sub-saharan-africa/overview. Accessed September 10, 2020.

16. UNAIDS/WHO/UNICEF. Global AIDS monitoring, spectrum estimates (UNAIDS/WHO) and WHO HIV country intelligence. 2017.

17. Yitayew YA, Bekele DM, Demissie BW, Menji ZA. Mother to child transmission of HIV and associated factors among HIV exposed infants at public health facilities, Dessie Town, Ethiopia. HIV AIDS (Auckl). 2019;11:343-350.

18. CSA/Ethiopia CSA. Ethiopian demographic health survey. Addis Ababa, Ehiopia; 2016:1-63.

19. Ethiopia FDRo. Country progress report on the HIV response. 2014:1-50

20. Gourlay A, Birdthistle I, Mburu G, Iorpenda K, Wringe A. Barriers and facilitating factors to the uptake of antiretroviral drugs for prevention of mother-to-child transmission of HIV in sub-Saharan Africa: a systematic review. J Int AIDS Soc. 2013;16(1):18588.
21. Start Free. Stay free, AIDS free- a super-fast-track framework for ending AIDS among children, adolescents and young women by 2020. 2016.

22. World Health Organization. Global guidance on criteria and processes for validation: elimination of mother-to-child transmission of HIV and syphilis. 2017.

23. Lyatuu M, Msamanga G, Kalinga A. Clients' satisfaction with services for prevention of mother-to-child transmission of HIV in Dodoma Rural district. East Afr J Public Health. 2008;5(3):174-179.

24. Barker PM, Mphatswe W, Rollins N. Antiretroviral drugs in the cupboard are not enough: the impact of health systems' performance on mother-to-child transmission of HIV. J Acquir Immune Defic Syndr. 2011;56(2):e45-e48. doi:10.1097/QAI.0b013e3181fdbf20

25. Bachore BB, Tafese F, Gebissa F, Mekango DE. Quality of prevention of mother to child transmission (PMTCT) of HIV services in public hospitals of Hadiya Zone, Southern Ethiopia. Health Res Policy Syst. 2018;05(02). doi:10.21767/2254-9137.100092

26. Asefa A, Mitike G. Prevention of mother-to-child transmission (PMTCT) of HIV services in Adama town, Ethiopia: clients' satisfaction and challenges experienced by service providers. BMC Pregnancy Childbirth. 2014;14(1):57. doi:10.1186/1471-2393-14-57

27. Ejigu Y, Tadesse B. HIV testing during pregnancy for prevention of mother-to-child transmission of HIV in Ethiopia. PLoS One. 2018;13 (8):e0201886. doi:10.1371/journal.pone.0201886

28. Demographic and Health Indicators. Available from: https://en.wiki pedia.org/wiki/Dire_Dawa. Accessed September 10, 2020.

29. Ginwalla S, Grant A, Day J, et al. Use of UNAIDS tools to evaluate HIV voluntary counselling and testing services for mineworkers in South Africa. AIDS Care. 2002;14(5):707-726. doi:10.1080/09540 12021000005533

30. Deressa W, Seme A, Asefa A, Teshome G, Enqusellassie F. Utilization of PMTCT services and associated factors among pregnant women attending antenatal clinics in Addis Ababa, Ethiopia. BMC Pregnancy Childbirth. 2014;14(1):328. doi:10.1186/14712393-14-328

31. Ashipa T, Ighedosa S. Assessment of clients' satisfaction with the PMTCT counselling service in Benin city, Edo state, Nigeria. $J$ Med Biomed Res. 2013;12(2):150-165.

32. Feyera A, Megerssa B, Legesse D, Hailemichael F. Prevention of mother to child transmission of HIV/AIDS: service utilization and associated factors among selected public health facilities in Ethiopia. Med Pract Rev. 2017;8(1):1-13.

33. Price MA, Naburi H, Mujinja P, et al. Predictors of patient dissatisfaction with services for prevention of mother-to-child transmission of HIV in Dar es Salaam, Tanzania. PLoS One. 2016;11(10): e0165121. doi:10.1371/journal.pone.0165121

34. Merga H, Woldemichael K, Dube L. Utilization of prevention of mother-to-child transmission of HIV services and associated factors among antenatal care attending mothers in Sebeta Town, Central Ethiopia. Adv Public Health. 2016;2016:1-10. doi:10.1155/2016/ 6250898

35. Bayou NB, Tsehay YE. Quality of PMTCT services in gebretsadiq shawo memorial hospital, Kafa Zone, South West Ethiopia: a descriptive study. Open Access Lib J. 2015;2(05):1.

36. Pearson L, Gandhi M, Admasu K, Keyes EB. User fees and maternity services in Ethiopia. Int J Gynaecol Obstet. 2011;115(3):310-315. doi:10.1016/j.ijgo.2011.09.007

37. Melese T, Gebrehiwot Y, Bisetegne D, Habte D. Assessment of client satisfaction in labor and delivery services at a maternity referral hospital in Ethiopia. Pan Afr Med J. 2014;17. doi:10.11604/ pamj.2014.17.76.3189

38. Westheimer EF, Urassa W, Msamanga G, et al. Acceptance of HIV testing among pregnant women in Dar-es-Salaam, Tanzania. J Acquir Immune Defic Syndr. 2004;37(1):1197-1205. doi:10.1097/01. qai.0000120806.43677.ff 
39. Ismail H, Ali A. Pregnant women's satisfaction and comprehension level of information given during HIV counseling and testing for PMTCT in public health facilities in Addis Ababa. Ethiop $J$ Health Dev. 2011;25(2):126-134.

40. Phillips KA, Bayer R, Chen JL. New centers for disease control and prevention's guidelines on HIV counseling and testing for the general population and pregnant women. J Acquir Immune Defic Syndr. 2003;32(2):182-191. doi:10.1097/00126334-200302010-00010
41. Branson BM, Handsfield HH, Lampe MA, et al. Revised recommendations for HIV testing of adults, adolescents, and pregnant women in health-care settings. Morb Mortal Wkly Rep. 2006;55(14):1-CE.

\section{Publish your work in this journal}

HIV/AIDS - Research and Palliative Care is an international, peerreviewed open-access journal focusing on advances in research in HIV, its clinical progression and management options including antiviral treatment, palliative care and public healthcare policies to control viral spread. The manuscript management system is completely online and includes a very quick and fair peer-review system, which is all easy to use. Visit http://www.dovepress.com/testimonials.php to read real quotes from published authors. 